\title{
BIBECHANA
}

ISSN 2091-0762 (Print), 2382-5340 (Online)

Journal homepage: http://nepjol.info/index.php/BIBECHANA

Publisher: Department of Physics, Mahendra Morang A.M. Campus, TU, Biratnagar, Nepal

\section{Empirical model for estimation of global solar radiation at lowland region Biratnagar using satellite data}

\author{
Ganesh K. Shrestha ${ }^{1}$, Binod Pandey ${ }^{*}$, Usha Joshi ${ }^{2}$, Khem N. Poudyal ${ }^{1}$ \\ ${ }^{1}$ Institute of Engineering, Tribhuvan University, Kathmandu, Nepal \\ ${ }^{2}$ Department of Physics, Patan Multiple Campus, TU, Kathmandu, Nepal \\ *Email: pandeybinod@ioe.edu.np
}

\section{Article Information:}

Received: June 26, 2020

Accepted: December 7, 2020

Keywords:

Sunshine duration

Satellite data of GSR Regression coefficient

linear model

Statistical test

\begin{abstract}
This study proposes to find the regression coefficient of modified Angstrom type model for the estimation of global solar radiation (GSR) in lowland Biratnagar (Lat. 26.5 $\mathrm{N}$, Long. $87.3^{\circ} \mathrm{E}$ and Alt. $72 \mathrm{~m}$ ) using relative sunshine duration and satellite data of GSR. Using the regression technique, the empirical constants 0.29 and 0.56 are found in modified Angstrom model. Furthermore, Modified Angstrom model along with other linear models such as Glover and McCulloch model, Page model, Rietveld model and Turton's model are statistically assessed to evaluate the significance of models. Statistical test like MPE, MBE, RMSE and CC reveal that all these models are statistically significant. These findings can be utilized for other locations with high confidence level at the similar climatic locations of Nepal.
\end{abstract}

DOI: https://doi.org/10.3126/bibechana.v18i1.29689

This work is licensed under the Creative Commons CC BY-NC License. https://creativecommons.org/licenses/by-nc/4.0/

\section{Introduction}

Energy is a fundamental driving tool in global change. Fossil fuel has been playing a key role in global energy systems as well as technological, social and economic progress. However, use of fossil fuel increase by leaps and bounds since $20^{\text {th }}$ century has been releasing carbon on alarming rate. This leads to various repercussions like climate change which may wipe out the human civilization from the earth. So it is high time to explore and promote renewable energy technology for the sustainable development on low carbon trajectory $[1,2,3,4]$.

Solar energy is the energy from the sun which is emitted in the form of electromagnetic radiation. Solar energy, an ultimate source of all form of energy, is also a promising source of energy for the sustainable future. Solar radiation data are crucial in agriculture, evapotranspiration, architectural design, meteorology, hydrology, and the designing and sizing of solar energy systems. The development of 
database on the long term solar radiation is essential for evaluation of solar energy potential and other modelling applications. Indeed, efficient design, sizing, and performance of solar energy devices depend on the accuracy of the available insolation data of the site. This information is utilized in the design, cost analysis, and calculation of the efficiency of a project. Apart from this, assessment of various meteorological parameters like humidity, temperature, clearness index as well as sunshine hours for specific period is essential in the viability of solar related project $[3,4,5,6,7,8]$.

Ground measurement at site of interest by installing a thermopile sensor such as pyranometer or pyroheliometer is considered as most accurate and reliable way of obtaining global solar radiation data for solar energy system design.

However, continuous and long-term ground measurements is daunting because of high acquisition and maintenance costs, susceptibility of soiling as well as high power demand for operation of pyranometer[3,4]. For country like Nepal, it is difficult to setup good network of measuring station for long term measurement. Although, different study shows that the average GSR is about 4.23 $\mathrm{kWh} / \mathrm{m}^{2} /$ day and the sun shines for about 300 days in a year. The national average sunshine duration is about $6.8 \mathrm{hrs} /$ day. This study indicates that Nepal is rich in solar energy. But, to confirm this statement long term Continuous solar energy data are required $[8,9]$.

In order to overcome these difficulties we can develop an empirical models based on radiation data derived from satellite database and meteorological parameters. It is an alternative way to get solar database for research and development of solar energy systems.

There are various empirical models for estimating GSR using several meteorological data. The most commonly used model which relates the GSR to sunshine duration was first time developed by Angstrom [10]. Subsequently, other more models are introduced using sunshine duration, maximum and minimum temperature, relative humidity, rainfall, wind speed and so on $[8,11]$.

The main purpose of this paper is to determine the coefficients ' $a$ ' and ' $b$ ' from Angstrom's model as well as statistically assess the appropriateness of existing linear model like Glover and McCulloch model, Page model, Rietveld model and Turton's model for estimation of GSR in horizontal surface based on satellites data for Biratnagar, Nepal.

\section{Climatic Properties}

Biratnagar is the capital city of Province no 1, Nepal, lies at $26.5^{\circ} \mathrm{N}$ and $87.3^{\circ} \mathrm{E}$ at mean elevation of about $72 \mathrm{~m}$ from sea level. It is characterized by humid subtropical warm temperate climate where temperature normally varies from a minimum of $10.5^{0} \mathrm{C}$ for December to maximum of $33.9{ }^{\circ} \mathrm{C}$ for April with annual average of mean temperature normal of $24.2^{\circ} \mathrm{C}$. The annual average of precipitation is normally $1891.8 \mathrm{~mm}$, most of which falls during monsoon. July has the most rainfall, with an average of $530.8 \mathrm{~mm}$ and November is the driest month, with an average rainfall of $5.9 \mathrm{~mm}$ [12].

\section{Method}

\section{Methods of Instrumentation}

In the present study, the data of the bright sunshine hours for the Biratnagar were supplied from the Dept. of Hydrology and Meteorology. The monthly average data of global solar radiation on horizontal surface over the period of 22 years (1983-2005) was obtained from surface meteorological and solar energy (SSE) web portal supported by NASA LaRC [13].

There are various equations relating solar radiation as function of meteorological parameters like relative humidity, ambient temperature and sunshine hours. The first correlation proposed for estimating the monthly mean daily global solar radiation on a horizontal surface using the sunshine duration data is due to Angstrom [10] and Prescott [14] have put 
the Angstrom correlation in more convenient form as

$$
\frac{\overline{\mathrm{H}}_{\mathrm{g}}}{\overline{\mathrm{H}}_{\mathrm{o}}}=\mathrm{a}+\mathrm{b}\left(\frac{\overline{\mathrm{n}}}{\overline{\mathrm{N}}}\right)
$$

where, constants 'a' and ' $b$ ' are empirical constants estimated using regression analysis.

The physical significance of the regression constants is that ' $a$ ' represents the case of overall atmospheric transmission for an overcast sky condition. It means that $\overline{\mathrm{n}} / \overline{\mathrm{N}}$ is nearly equal to zero. In other hands, ' $\mathrm{b}$ ' is the rate of increase of $\overline{\mathrm{H}}_{\mathrm{g}} / \overline{\mathrm{H}}_{\mathrm{o}}$ with mean of $n / \mathrm{N}$. The sum of 'a' and ' $b$ ' significantly represents the overall transmission under clear sky index. $\mathrm{N}$ is the day length (hours), $\mathrm{n}$ is bright sunshine hours, $\overline{\mathrm{H}}_{\mathrm{g}}$ is the monthly average of daily global solar radiation, measured on horizontal surface, $\overline{\mathrm{H}}_{\mathrm{o}}$ is the monthly average of extra-terrestrial solar radiation, $\bar{n}$ is the monthly average daily sunshine hours and $\overline{\mathrm{N}}$ is monthly average day length in hours. The monthly average daily extra-terrestrial solar radiation $\overline{\mathrm{H}}_{\mathrm{o}}$ is calculated using

$$
\overline{\mathrm{H}}_{\mathrm{o}}=\frac{1}{\mathrm{n}_{2}-\mathrm{n}_{1}} \sum_{\mathrm{n}_{1}}^{\mathrm{n}_{2}} \mathrm{H}_{\mathrm{o}}
$$

where $n_{1}$ and $n_{2}$ are the day numbers at beginning and end of the month respectively

And, $\mathrm{H}_{\mathrm{o}}$ is given by

$$
\begin{aligned}
& \mathrm{H}_{\mathrm{o}}=\frac{24}{\pi} \mathrm{I}_{\mathrm{sc}}(1+ \\
& \left.0.033 \cos \frac{360}{365} \mathrm{n}\right)\left(\omega \frac{\pi}{180} \sin \emptyset \sin \delta+\right. \\
& \cos \emptyset \cos \delta \sin \omega) \\
& \delta=23.45 \sin \left(\frac{360}{365}(284+\mathrm{n})\right) \\
& \mathrm{N}=\frac{2}{15} \cos ^{-1}(-\tan \emptyset \tan \delta) \\
& \omega=\cos ^{-1}(-\tan \emptyset \tan \delta)
\end{aligned}
$$

where $_{\text {sc }}$ is the solar constant,$\varnothing$ is the latitude of the site,$\delta$ is the solar declination, $\omega$ is the hours angle , $\mathrm{N}$ is the day length, $\mathrm{n}$ is the day of the year starting from $1^{\text {st }}$ of January $[15,16]$.

The Angstrom-Prescott regression equation is commonly used simplest model to estimate the average global solar radiation on horizontal surface that is used to estimate the monthly average daily global solar radiation on a horizontal surface in
Biratnagar. The solar radiation reaching the earth's surface can be estimated by empirical model when measured data are available.

The result of our model is compared with four other previously reported linear models. The models are:

Turton's model, which developed an average regression constants for the humid tropical climate as:

$$
\frac{\overline{\mathrm{H}}_{\mathrm{g}}}{\overline{\mathrm{H}}_{\mathrm{o}}}=0.34+0.4\left(\frac{\overline{\mathrm{n}}}{\overline{\mathrm{N}}}\right)
$$

Rietveld's model is believed to be universal in nature given by:

$$
\frac{\overline{\mathrm{H}}_{\mathrm{g}}}{\overline{\mathrm{H}}_{\mathrm{o}}}=0.18+0.62\left(\frac{\overline{\bar{n}}}{\overline{\mathrm{N}}}\right)
$$

McCulloch's model takes into account the latitude effect and is valid for $\varnothing<60^{\circ}$ given by

$$
\frac{\overline{\mathrm{H}}_{\mathrm{g}}}{\overline{\mathrm{H}}_{\mathrm{o}}}=0.29 \cos \emptyset+0.52\left(\frac{\overline{\mathrm{n}}}{\overline{\mathrm{N}}}\right)
$$

Page model is as follows:

$$
\frac{\overline{\mathrm{H}}_{\mathrm{g}}}{\overline{\mathrm{H}}_{\mathrm{o}}}=0.23+0.48\left(\frac{\overline{\bar{n}}}{\overline{\mathrm{N}}}\right)
$$

These models are applied to the sunshine data at Biratnagar. The estimated and measured value of average daily global radiation on the horizontal surface is compared to find the best correlation with the measured global solar radiation. The results are as shown in table- $2[15,16]$.

\section{Method of Statistical Comparison}

The results of these models were assessed by the statistical tests like Mean Percentage Error (MPE), Root Mean Square Error (RMSE), Mean Bias Error (MBE), and correlation coefficient (CC). MPE, MBE, RMSE and CC are the Statistical gauges with which one can compare the models. The result of Statistical assessment is shown in table-3. The MPE can be defined as the percentage deviation of the monthly average daily radiation values estimated by the model used from the measured values. The signs of errors are neglected and percentage errors are added up to obtain the mean.

$$
\text { MPE }=\left(\frac{1}{n}\right) \sum\left[\frac{\mathrm{H}_{\mathrm{est}}-\mathrm{H}_{\mathrm{mes}}}{\mathrm{H}_{\mathrm{mes}}}\right]
$$


The Mean Bias Error gives an idea of the difference between the monthly average daily radiation values estimated by the model used and the measured value. A positive value shows over estimation and a negative value is under estimation. Over estimation of an individual observation will cancel under estimation in a separate observation.

$$
\operatorname{MBE}=\left(\frac{1}{n}\right) \sum\left[\mathrm{H}_{\mathrm{est}}-\mathrm{H}_{\mathrm{mes}}\right]
$$

It gives the long term performance of the correlation by allowing a comparison of the actual deviation between calculated and measured values term by term. The Root Mean Square Error yields the same idea of the divergence between the monthly average daily radiation values estimated by the model used and the measured values as given by MBE. However the information is relevant to the short-term performance.

$$
\text { RMSE }=\sqrt{\frac{\sum\left(\mathrm{H}_{\mathrm{est}}-\mathrm{H}_{\mathrm{mes}}\right)^{2}}{\mathrm{n}}}
$$

The correlation coefficient (CC) is the measure of linear relationship between the estimated and measured values. It is given by

The correlation coefficient (CC) is the measure of linear relationship between the estimated and measured values. It is given by

$$
\mathrm{CC}=\frac{\sum\left(\mathrm{H}_{\mathrm{est}}-\overline{\mathrm{H}}_{\mathrm{est}}\right)\left(\mathrm{H}_{\mathrm{mes}}-\overline{\mathrm{H}}_{\mathrm{mes}}\right)}{\sqrt{\left[\sum\left(\mathrm{H}_{\mathrm{est}}-\overline{\mathrm{H}}_{\mathrm{est}}\right)^{2}\right]\left[\sum\left(\mathrm{H}_{\mathrm{mes}}-\overline{\mathrm{H}}_{\mathrm{mes}}\right)^{2}\right]}} \ldots
$$

where $\mathrm{H}_{\text {est }}$ is calculated value and

Table -1: Meteorological Data and Solar Radiation at Lowland Biratnagar.

\begin{tabular}{|c|c|c|c|c|c|c|}
\hline Month & $\begin{array}{c}\overline{\mathrm{H}}_{\mathrm{o}} \\
\left(\mathrm{MJ} / \mathrm{m}^{2} / \text { day }\right)\end{array}$ & $\begin{array}{c}\overline{\mathrm{H}}_{\mathrm{g}} \\
\left(\mathrm{MJ} / \mathrm{m}^{2} / \text { day }\right)\end{array}$ & $\begin{array}{c}\mathrm{KT} \\
\left(\overline{\mathrm{H}}_{\mathrm{g}} / \overline{\mathrm{H}}_{\mathrm{o}}\right)\end{array}$ & $\begin{array}{c}\overline{\mathrm{N}} \\
(\text { Hours })\end{array}$ & $\begin{array}{c}\overline{\mathrm{n}} \\
(\text { Hours })\end{array}$ & $\overline{\mathrm{n}} / \overline{\mathrm{N}}$ \\
\hline Jan & 23.37 & 15.12 & 0.65 & 10.54 & 6.15 & 0.58 \\
\hline Feb & 27.61 & 18.68 & 0.68 & 11.11 & 7.72 & 0.70 \\
\hline Mar & 32.95 & 22.32 & 0.68 & 11.87 & 7.26 & 0.61 \\
\hline Apr & 37.42 & 23.98 & 0.64 & 12.66 & 8.61 & 0.68 \\
\hline May & 39.90 & 23.47 & 0.59 & 13.32 & 6.83 & 0.51 \\
\hline Jun & 40.66 & 19.48 & 0.48 & 13.63 & 3.96 & 0.29 \\
\hline Jul & 40.09 & 15.88 & 0.40 & 13.46 & 3.35 & 0.25 \\
\hline Aug & 37.99 & 16.31 & 0.43 & 12.88 & 3.58 & 0.28 \\
\hline Sep & 34.05 & 15.62 & 0.46 & 12.11 & 5.44 & 0.45 \\
\hline Oct & 28.81 & 17.78 & 0.62 & 11.31 & 8.00 & 0.71 \\
\hline Nov & 24.11 & 17.06 & 0.71 & 10.66 & 7.44 & 0.70 \\
\hline Dec & 22.00 & 14.90 & 0.68 & 10.36 & 5.33 & 0.51 \\
\hline
\end{tabular}

$\mathrm{H}_{\text {mes }}$ is the measured value of the average daily global solar radiation and $\mathrm{n}$ is the number of observations. $\overline{\mathrm{H}}_{\text {est }}$ and $\overline{\mathrm{H}}_{\text {mes }}$ are the mean estimated and measured values of global solar radiation on horizontal surface. The ideal value for MPE, MBE and RMSE would be Zero. However, ideal value of $\mathrm{CC}$ should be 1 . RMSE can never be negative and the lower the value the more accurate the estimate [15].

\section{Results and Discussion}

The input parameters used for the estimation of monthly average global solar radiation at lowland region, Biratnagar are given in Table-1. Data of Table-2 shows the results of statistical test along with the models. Data of Table-3 depicts the estimated values of monthly average global solar radiation by using these linear models.

Figure-1 shows that the sunshine duration (SSD) varies as rotation of earth and local weather condition. Its maximum and minimum values, i.e. 8.61 hours and 3.35 hours are found on April and 
July. Data of Table-1 shows that the sunshine duration is more than 6 hours per day except in June, July, August and September. In those months the sunshine hour and GSR is comparatively lower due to clouds and rainfall.

Figure.-2 shows the monthly variation of relative sunshine hours $(\overline{\mathrm{n}} / \overline{\mathrm{N}})$ and clearness index $(\mathrm{KT})$ at Biratnagar. The poor sky condition due to high relative humidity and rainfall cause depression in the month of July and August. Where $\overline{\mathrm{n}} / \overline{\mathrm{N}}$ goes as low as 0.25 and $\mathrm{KT}$ reaches a minimum value of 0.40 for July and 0.43 for August.
Figure-3 shows that both measured and estimated values of GSR are strongly correlated as the correlation coefficient is greater than 0.85 for ever model. The value of MBE is slightly positive for A$P$ model which indicates overestimation than measured value. For rest of the models, the MBE is negative which show underestimation than measured value. The RMSE for A-P model is least and greatest for the Page model.

Table-2: Summary of empiricals models with statistical indicators.

\begin{tabular}{|c|c|c|c|c|c|}
\hline Model Name & Empirical Model & MPE $(\%)$ & MBE & RMSE & CC \\
\hline Angstrom-Prescott Model & $\overline{\mathrm{H}}_{\mathrm{g}} / \overline{\mathrm{H}}_{\mathrm{o}}=0.29+0.56(\overline{\mathrm{n}} / \overline{\mathrm{N}})$ & 1.50 & 0.25 & 1.50 & 0.89 \\
\hline Glover and McCulloch Model & $\overline{\mathrm{H}}_{\mathrm{g}} / \overline{\mathrm{H}}_{\mathrm{o}}=0.29 \cos (\varphi)+0.52(\overline{\mathrm{n}} / \overline{\mathrm{N}})$ & 7.50 & -1.40 & 1.99 & 0.90 \\
\hline Page Model & $\overline{\mathrm{H}}_{\mathrm{g}} / \overline{\mathrm{H}}_{\mathrm{o}}=0.23+0.48(\overline{\mathrm{n}} / \overline{\mathrm{N}})$ & 16.34 & -3.02 & 3.32 & 0.90 \\
\hline Rietveld Model & $\overline{\mathrm{H}}_{\mathrm{g}} / \overline{\mathrm{H}}_{\mathrm{o}}=0.18+0.62(\overline{\mathrm{n}} / \overline{\mathrm{N}})$ & 12.94 & -2.36 & 2.81 & 0.88 \\
\hline Turton's Model & $\overline{\mathrm{H}}_{\mathrm{g}} / \overline{\mathrm{H}}_{\mathrm{o}}=0.34+0.4(\overline{\mathrm{n}} / \overline{\mathrm{N}})$ & 3.67 & -0.74 & 1.81 & 0.85 \\
\hline
\end{tabular}

Table-3: Estimated value of global solar radiation $\left(\mathrm{MJ} / \mathrm{m}^{2} /\right.$ day $)$ by differnt models.

\begin{tabular}{|c|c|c|c|c|c|}
\hline Month & A-P Model & G M Model & Page Model & Rietveld Model & Turton's Model \\
\hline Jan & 14.48 & 13.21 & 11.97 & 12.72 & 13.46 \\
\hline Feb & 18.92 & 17.30 & 15.70 & 17.02 & 17.22 \\
\hline Mar & 20.97 & 19.15 & 17.36 & 18.54 & 19.38 \\
\hline Apr & 25.17 & 23.00 & 20.87 & 22.57 & 22.96 \\
\hline May & 23.04 & 21.01 & 19.01 & 19.88 & 21.76 \\
\hline Jun & 18.43 & 16.72 & 15.04 & 14.66 & 18.58 \\
\hline Jul & 17.24 & 15.61 & 14.03 & 13.42 & 17.64 \\
\hline Aug & 16.99 & 15.41 & 13.85 & 13.43 & 17.20 \\
\hline Sep & 18.66 & 16.99 & 15.35 & 15.80 & 17.90 \\
\hline Oct & 20.20 & 18.47 & 16.77 & 18.22 & 18.34 \\
\hline Nov & 16.72 & 15.28 & 13.87 & 15.04 & 15.20 \\
\hline Dec & 12.74 & 11.61 & 10.51 & 10.99 & 12.02 \\
\hline
\end{tabular}




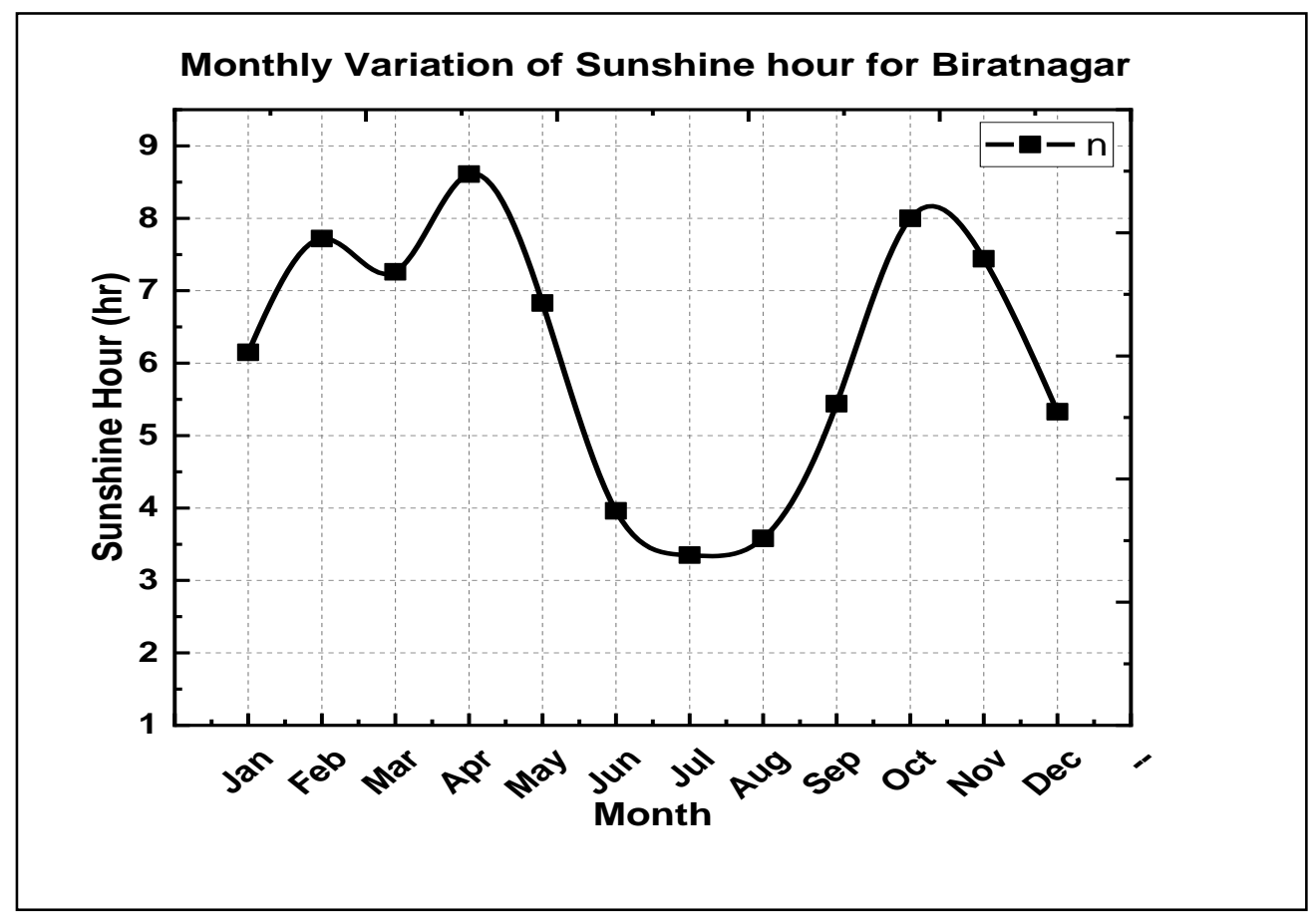

Fig.1: Monthly variation of Sunshine hours.

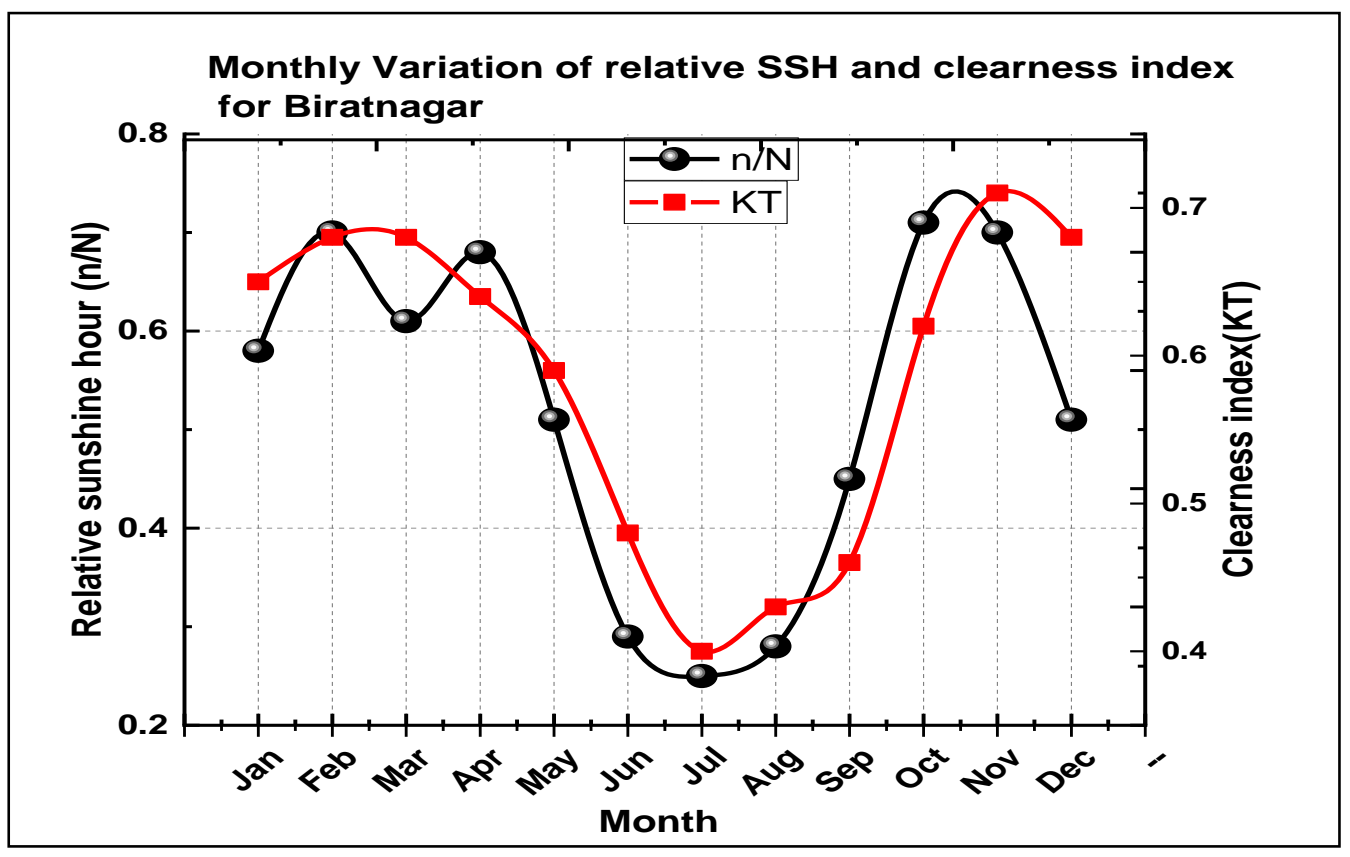

Fig. 2: Monthly Variation of Clearness Index and Relative Sunshine Hour. 


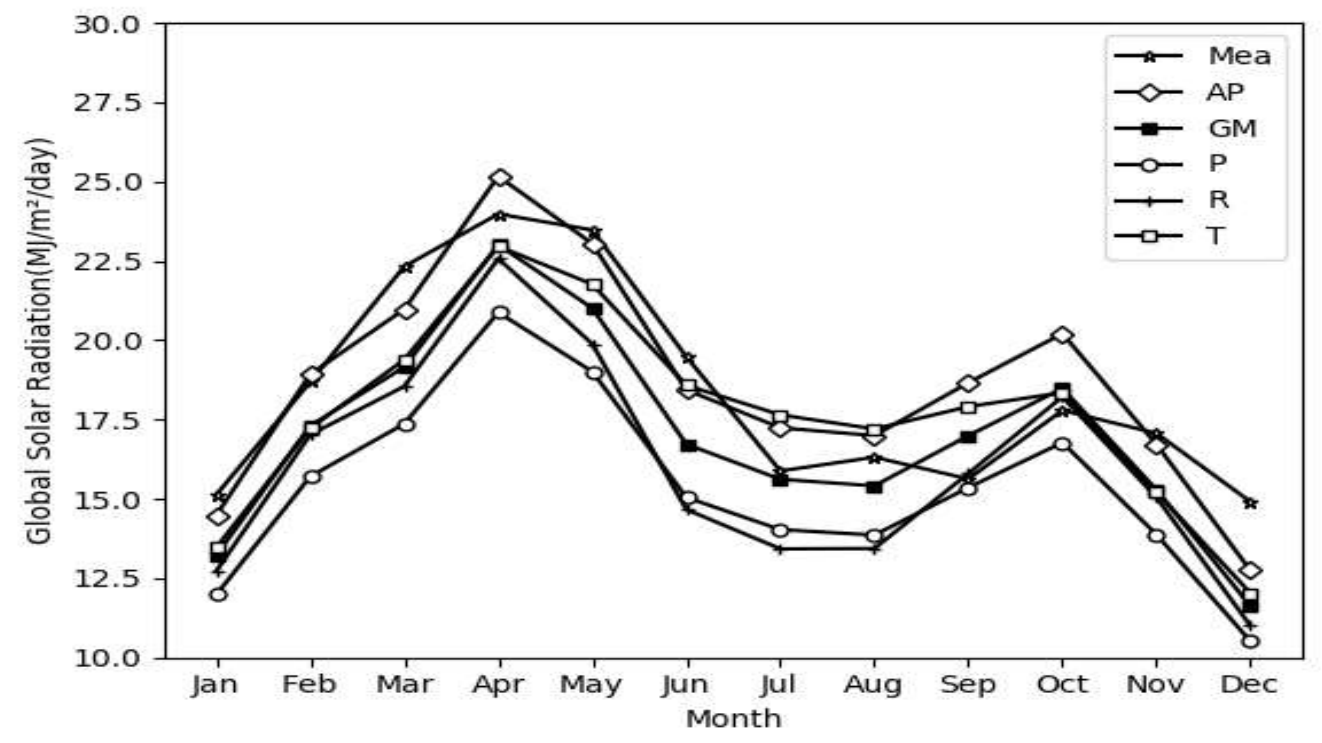

Fig.3: Comparison of estimated global solar radiation using different models with measured value.

\section{Conclusion}

By the regression analysis of GSR satellite data with sunshine hour we found the correlation equation based on Angstrom-Prescott model and statistically compare existing linear models. Statistical assessment shows that all these linear models are significant for the estimation of Global solar radiation. However, overall performance parameter MPE (\%), MBE, RMSE and CC of A-P model are found to be $1.50,0.25,1.50$ and 0.89 respectively which show superiority of A-P models over rest of the models. Furthermore, among the existing linear models Turton's model is best so it could be preferred for estimation of global solar radiation in location with similar climatic condition in absence of reliable data for development of new model.

\section{Acknowledgement}

Authors are grateful to express their sincere thanks to Department of Hydrology and Meteorology (DHM), Government of Nepal for providing the meteorological data and NASA Langley Research Centre (LCR) power project funded through the
NASA Earth Science/Applied Science Program for providing data on monthly average daily global solar radiation. We would like to special thanks to faculty members and staffs of Department of Applied Sciences and Chemical Engineering, IOE, Pulchowk Campus, Tribhuvan University.

\section{References}

[1] https://ourworldindata.org/fossil-fuels

[2] B. Pandey et al., Prediction of global solar radiation using meteorological parameters on empirical model at mountain region Jumla, Nepal, Research Journal of Chemical Sciences. 8(2018) 23-29.

[3] J. L. Chen et al., Empirical models for estimating monthly global solar radiation: A most comprehensive review and comparative case study in China, Renewable and Sustainable Energy Reviews. 108 (2019) 91-111. https://doi.org/10.1016/j.rser.2019.03.033.

[4] F. Besharat et al., Empirical models for estimating global solar radiation: A review and case study, Renewable and Sustainable Energy Reviews. 21(2013)789-821.

http://dx.doi.org/10.1016/j.rser.2012.12.043. 
[5] B. Pandey et al., Estimation of Monthly average daily diffuse solar radiation using empirical models for Kathmandu Nepal, Journal of Nepal Physical Society. 5(2019) 6-13. https://doi.org/10.3126/inphyssoc.v5i1.26875.

[6] M. T. Sanan et al., Measurement of Global and Direct Normal Solar Energy Radiation in Seri skandar and Comparison with other Cities of Malaysia, Case Studies in Thermal Engineering. 18(2020).

https://doi.org/10.1016/j.csite.2020.100591.

[7] O. M. Boluwaji, O. D. Onyedi, Comparative Study of Ground Measured, Satellite-Derived and Estimated Global Solar Radiation Data in Nigeria, Journal of Solar Energy .(2016). https://doi.org/10.1155/2016/8197389.

[8] K. N. Poudyal et al., Solar Radiation Potential at Four Sites of Nepal, Journal of the Institute of Engineering. 8(2011) 189- 197. https://doi.org/10.3126/jie.v8i3.5944.

[9] K.R. Adhikari et al., Solar Energy Potential in Nepal and Global Context, Journal of the Institute of Engineering. 9(2014) 95- 106. https://doi.org/10.3126/jie.v9i1.10675.
[10] A. Angstrom, Solar and terrestrial radiation, Q J Roy Meteor Soc. 50(1924) 121-125.

[11] K. N. Poudyal et al., Estimation of the daily global solar radiation, Nepal experience, Measurement. 46(2013)1807-1817. http://dx.doi.org/10.1016/j.measurement.2013.0 1.012.

[12] Climate. Retrieved from Department of Hydrology and Meterology: (2020) www.dhm.gov.np

[13] DATA ACCESS Retrieved from NASA Prediction of Worldwide Energy Resources: (2020) https://power.larc.nasa.gov

[14] J.A. Prescott, Evaporation from a water surface in relation to solar radiation, Tran Roy Soc South Aust. 64 (1940) 114-118.

[15] M. Iqbal, An introduction to solar radiation, Academic Press, New York (1983).

[16] J.A. Duffie and W.A. Beckman, Solar Engineering of Thermal Processes, 2nd edition, John- Wiley and Sons, New York (1991). 